FALIŃsKi J. B. 1990. Kartografia geobotaniczna 1. s. 284. Państwowe Przedsiębiorstwo Wydawnictw Kartograficznych, Warszawa - Wrocław.

Jackowiak B., Celka Z., Chmiel J., Latowski K. \& Żukowski W. 2007. Red list of vascular flora of Wielkopolska (Poland). - Biodiversity: Research and Conservation 5-8: 95-127.

Kaźmierczakowa R., Bloch-Oreowska J., Celka Z., Cwener A., Dajdok Z., Michalska-Hejduk D.,

PAWLIKowsKi P., SZCZEŚNIAK E. \& ZIARNEK K. 2016. Polska czerwona lista paprotników i roślin kwiatowych. s. 44. Instytut Ochrony Przyrody Polskiej Akademii Nauk, Kraków.

KĄCKI Z., DAJdoK Z. \& SzCZEśŚnIAK E. 2003. Czerwona lista roślin naczyniowych Dolnego Śląska. - W:

Z. KĄCKI (red.), Zagrożone gatunki flory naczyniowej Dolnego Śląska, s. 19-56. Instytut Biologii Roślin, Uniwersytet Wrocławski, Polskie Towarzystwo Przyjaciół Przyrody „pro Natura”, Wrocław.

ŁAZARSKI G. 2018. Thymelaea passerina (Thymelaeaceae) - nowy archeofit Gór Świętokrzyskich. - Fragmenta Floristica et Geobotanica Polonica 25(2): 289-292.

Matuszkiewicz W. 2008. Przewodnik do oznaczania zbiorowisk roślinnych Polski. Vademecum Geobotanicum. 3. s. 537. Wydawnictwo Naukowe PWN, Warszawa.

Meusel H., JÄger E. J., Rauschert S. \& Weinert E. 1978. Vergleichende Chorologie der Zentraleuropäischen Flora. Bd. 2. Text \& Karten. s. 171. G. Fischer Verlag, Jena.

NowaK A., NowAK S. \& SpąEK K. 2008. Red List of vascular plants of Opole province. - Opole Scientific Society, Nature Journal 41: 141-158.

Parusel J. B. \& Urbisz A. (red.). 2012. Czerwona lista roślin naczyniowych województwa śląskiego. - Raporty Opinie 6(1): 105-177.

WęGRZYNEK B. 2014. EN Bupleurum rotundifolium L. Przewiercień okrągłolistny. - W: R. KAŹMIERCZAKowA, K. ZarZYCKI \& Z. MireK (red.), Polska czerwona księga roślin. Paprotniki i rośliny naczyniowe, s. 354-356. Instytut Ochrony Przyrody PAN, Kraków.

ZAJĄC A. 1978. Założenia metodyczne „Atlasu rozmieszczenia roślin naczyniowych w Polsce”. - Wiadomości Botaniczne 22(3): 145-155.

ZAJĄC A. \& ZAJAC M. (red.). 2001. Atlas rozmieszczenia roślin naczyniowych w Polsce. s. xii + 716. Nakładem Pracowni Chorologii Komputerowej Instytutu Botaniki Uniwersytetu Jagiellońskiego, Kraków.

ZAJAC M., ZAJAC A. \& TOKARSKA-GUZIK B. 2009. Extinct and endangered archaeophytes and the dynamics of their diversity in Poland. - Biodiversity: Research and Conservation 13: 17-24.

Grzegorz ŁaZARski, Wydziat Nauk Ścistych i Przyrodniczych, Uniwersytet PrzyrodniczoHumanistyczny w Siedlcach, ul. Prusa 14,08-110 Siedlce, Polska; e-mail: grzegorz.lazarski@ gmail.com

Wptynęto: 14.01.2020 r.; przyjęto do druku: 28.12.2020 r.

DOI: https://doi.org/10.35535/ffgp-2020-0049

\title{
Preferencje żywicielskie Cuscuta lupuliformis (Convolvulaceae) w Sandomierzu
}

Rośliny pasożytnicze stanowią około 1\% światowej flory, co stanowi około 4500 gatunków (HEIDE-JøRGENSEN 2008). Blisko 200 z nich to przedstawiciele rodzaju Cuscuta L. (kanianka) (COSTEA i in. 2015). W Polsce dotychczas notowano 10 gatunków omawianego rodzaju, 
pośród których trzy posiadają status efemerofitów, natomiast jeden (Cuscuta epilinum) uznawany jest za wymarły (MIREK i in. 2002).

Cuscuta to kosmopolityczny rodzaj należący do rodziny Convolvulaceae, którego przedstawiciele zasiedlają zróżnicowane siedliska (CosteA i in. 2015). Są to rośliny holopasożytnicze (KAISER i in. 2015). Infekują naziemne części roślin żywicielskich (Gajewski 1962; Podbielkowski \& Podbielkowska 1992). W zależności od klimatu w jakim występują mogą być jednoroczne lub wieloletnie (COSTEA \& TARDIF 2006). Część gatunków kanianek pasożytuje na jednym lub kilku gatunkach blisko ze sobą spokrewnionych, pozostałe wykazują szeroki zakres tolerancji wobec gospodarzy. Przedstawiciele rodzin Poaceae oraz Cyperaceae nie mogą być ich głównymi żywicielami (CoSTEA \& TARDIF 2006), między innymi z uwagi na budowę anatomiczną wiązek przewodzących oraz niską wydajność enzymów, biorących udział w rozpadzie tkanek jednoliściennych podczas wnikania pasożyta (SHARMA \& KAPOOR 2014). Jednak niektóre gatunki jednoliściennych moga pełnić rolę żywicieli wtórnych, choć często stanowią jedynie podporę dla intensywnie rozrastających się łodyg pasożyta (COSTEA \& TARDIF 2006).

Kanianki nie posiadają typowych korzeni, a ich funkcję pełnią rozmieszczone wzdłuż łodyg haustoria, którymi rośliny wnikają do tkanek gospodarza, pobierając wodę i produkty fotosyntezy (LANINI \& KoGAN 2005). Rośliny te posiadają wijące łodygi, którymi oplatają żywiciela w kierunku przeciwnym do ruchu wskazówek zegara (COSTEA \& TARDIF 2006) oraz zredukowane liście i obupłciowe kwiaty zapylane przez owady (SHARMA \& KAPOOR 2014).

Nasiona kanianek rozsiewane są najczęściej przez wiatr lub wodę, chociaż nie jest to sposób, który umożliwia rozprzestrzenianie się pasożytów na dalekie odległości (CosTEA $\mathrm{i}$ in. 2016). W przypadku kanianek, które są uporczywymi chwastami, jak np. Cuscuta campestris, znaczny udział w rozsiewaniu odgrywa człowiek, poprzez wymianę handlową zainfekowanych nasion roślin uprawnych pomiędzy krajami (COSTEA \& TRADIF 2006). Możliwe jest także rozsiewanie na drodze zoochorii, ponieważ nasiona kanianek przechodzą przez układ pokarmowy zwierząt w stanie nienaruszonym (BENVENUTI i in. 2005).

Gatunki z rodzaju Cuscuta wykazują duże zdolności regeneracyjne, co umożliwia im także rozmnażanie wegetatywne, np. w wyniku rozerwania pędów w trakcie wzrostu gospodarza, czy ingerencji człowieka lub zwierząt. U niektórych gatunków pasożytujących na żywicielach wieloletnich, jak w przypadku C. epithymum, zaobserwowano odkładanie tkanki miękiszowej, z której w kolejnym sezonie wegetacyjnym regenerują się młode pędy pasożyta (COSTEA \& TRADIF 2006).

Wiele gatunków kanianek w znaczący sposób zagraża uprawom na całym świecie (LANini \& KogAn 2005; Costea \& TARdif 2006; Costea i in. 2015). Inwazja pasożyta, między innymi w uprawach pomidorów (Lycopersicum esculentum), marchwi (Daucus carota), koniczyny (Trifolium sp.) i lucerny (Medicago sp.), obniża plony nawet o 50-90\%. W wielu przypadkach brak selektywnego herbicydu, który mógłby zwalczyć kanianki nie niszcząc upraw (LANINI \& KOGAN 2005). Jednym ze sposobów zwalczania pasożytów jest płodozmian. Skuteczność tej metody utrudnia jednak czas, jaki nasiona kanianek mogą przetrwać w glebie, gdyż posiadają one zdolność kiełkowania przez co najmniej 10 lat (COSTEA \& TARDIF 2006). W Polsce nie zaobserwowano dotychczas istotnych szkód 
w uprawach spowodowanych przez kanianki. Być może jest to związane z faktem, iż w klimacie umiarkowanym są to rośliny jednoroczne (COSTEA \& TARDIF 2006). Mimo iż gatunki rodzaju Cuscuta w wielu krajach zagrażają uprawom, posiadają także szerokie zastosowanie w tradycyjnej, jak i nowoczesnej medycynie (SHARMA \& KAPOOR 2014).

Cuscuta lupuliformis Krock. (kanianka wielka) osiąga największe rozmiary spośród wszystkich gatunków kanianek występujących na terenie Polski. Pasożytuje najczęściej na drzewach i krzewach z rodzaju Salix (WAYDA 1999). Badania prowadzone na Węgrzech wskazały 99 żywicieli głównych oraz przypadkowych kanianki wielkiej (BARÁTH \& CSIKY 2012). Gatunek ten jest częścią nadrzecznych zbiorowisk roślinnych zaliczanych do zespołu Cuscuto-Convolvuletum (KĘPCZYŃSKi \& RUTKOWSKI 1981; BORYSIAK 1994). Wraz z Rubus caesius może tworzyć zbiorowisko Cuscuto lupuliformis-Rubetum caesii, które po raz pierwszy wyodrębnione zostało na terenie Niemiec w okolicy dolnego Renu (SCHMITZ \& LÖSCH 1995). Typowym siedliskiem kanianki wielkiej są tereny zalewowe (BARÁTH \& CSIKY 2012). W Polsce rozprzestrzenia się wzdłuż dolin dużych rzek, głównie Wisły i Odry. Związane jest to zapewne z wytwarzaniem ciężkich nasion, których rozsiewanie umożliwiają wezbrania wód (WAYDA 1999). W skali kraju C. lupuliformis nie należy do rzadkich gatunków (WAYDA 1999), jednak lokalnie, np. na terenie Poznania, jest narażona na wyginięcie (DYDERSKI \& WrOŃSKA-PILAREK 2015).

Celem niniejszego opracowania jest przedstawienie rozmaitości żywicieli Cuscuta lupuliformis, rozprzestrzeniającej się w Sandomierzu wzdłuż koryta Wisły, ze wskazaniem gatunków przez nią preferowanych oraz oceną stopnia rozwoju pasożyta.

Badania terenowe prowadzono w latach 2017-2018 w obrębie granic administracyjnych miasta Sandomierz (miasto powiatowe województwa świętokrzyskiego, leżące częściowo na terenie makroregionu Kotlina Sandomierska oraz mezoregionu Wyżyna Sandomierska). Zastosowano siatkę kartogramu o boku $1 \mathrm{~km}$ zgodnie z metodyką przyjętą dla ATPOL (ZAJĄC 1978). Stanowiska Cuscuta lupuliformis notowano z uwzględnieniem gatunków żywicielskich oraz oceną stopnia rozwoju pasożyta. Materiał zielnikowy będący dokumentacją przeprowadzonych badań został zdeponowany w Herbarium Uniwersytetu Jana Kochanowskiego w Kielcach (KTC). Nomenklaturę podano za MirKIEM i in. (2002) oraz The Plant List (2013).

Podczas badań zlokalizowano 10 stanowisk Cuscuta lupuliformis. Powierzchnia rozprzestrzeniania się gatunku na terenie miasta wynosiła 6,2 ha, natomiast na poszczególnych stanowiskach zawierała się w przedziale od 0,1 ha do 2,2 ha. Cuscuta lupuliformis notowano wzdłuż koryta Wisły zarówno na terenach półnaturalnych, oddalonych od centrum miasta, jak również w miejscach o znacznym wpływie antropopresji. Na każdym ze stanowisk obserwowano intensywny rozwój pasożyta, który często tworzył zwarte płaty pokrywając niejednokrotnie niemal w całości swych żywicieli.

Cuscuta lupuliformis pasożytowała na przedstawicielach 14 rodzin. Przeważnie jednak porażane były gatunki reprezentujące: Salicaceae, Asteraceae i Rosaceae (Ryc. 1). Przeprowadzone badania wskazały 31 gatunków roślin żywicielskich, pośród których najczęściej atakowane były: Chaerophyllum bulbosum, Salix alba, S. fragilis, S. purpurea, S. viminalis, Rubus caesius i Urtica dioica, ze szczególnym uwzględnieniem (9 na 10 stanowisk) przedstawicieli rodzaju Salix (Tab. 1). Cuscuta lupuliformis intensywnie 


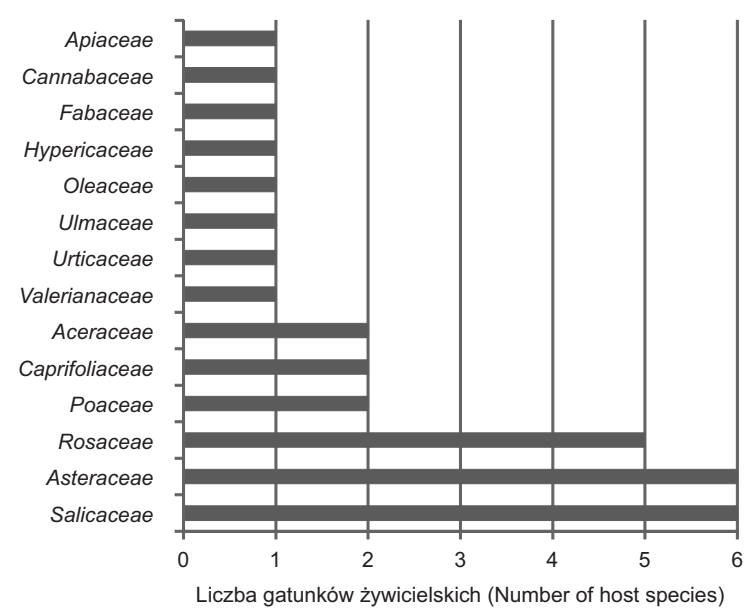

Ryc. 1. Wykaz rodzin i liczba gatunków zainfekowanych przez Cuscuta lupuliformis w Sandomierzu

Fig. 1. List of families and number of host species infected by Cuscuta lupuliformis in Sandomierz

rozwijała się w szczególności na 12 gatunkach. Zwarte płaty tworzyła nie tylko na przedstawicielach rodzaju Salix, ale także na: Acer platanoides, Artemisia vulgaris, Fraxinus excelsior, Lonicera tatarica, Rosa canina, Rubus caesius i Sambucus nigra. Liczba gatunków zainfekowanych przez $C$. lupuliformis na poszczególnych stanowiskach zawierała się w przedziale od 2 do 23. Ponadto na wszystkich notowanych stanowiskach obserwowano zdolność pasożytowania jednego osobnika kanianki na kilku niespokrewnionych ze sobą gatunkach.

Na uwagę zasługuje fakt, iż na stanowiskach zlokalizowanych bliżej centrum miasta obserwowano więcej gatunków infekowanych przez pasożyta w porównaniu do siedlisk półnaturalnych. Związane jest to niewątpliwie z występowaniem na tym terenie gatunków sadzonych, bądź dziczejących z upraw, a także roślin synantropijnych, w tym inwazyjnych, pojawiających się spontanicznie na terenach przekształconych przez człowieka. Przykładem powyższego jest stanowisko nr 7 (Tab. 1). Zlokalizowane jest ono w bezpośrednim sąsiedztwie sandomierskiej starówki, pomiędzy Al. Jana Pawła II, a starorzeczem Wisły. Pośród żywicieli notowanych na całym badanym terenie stwierdzono tu największy udział gatunków ozdobnych i jadalnych, takich jak: Lonicera tatarica, Prunus cerasifera, P. spinosa i Malus domestica, a także gatunki nie notowane na pozostałych stanowiskach, między innymi: Acer negundo, A. platanoides, Erigeron annuus, Fraxinus excelsior, Lactuca serriola, Sambucus nigra, Tanacetum vulgare i Ulmus minor. Określenie czy na ten stan ma wpływ występowanie siedlisk antropogenicznych, zaburzonych, dostępność specyficznych gatunków-żywicieli, czy jest to również efekt położenia miasta w bliskim sąsiedztwie Wisły wymaga dalszych badań.

Interesujący jest fakt atakowania przez kaniankę gatunków roślin z rodziny Rosaceae, w szczególności: Malus domestica, Prunus cerasifera czy P. spinosa, ponieważ są to rośliny uprawne. Jak zostało wspomniane na wstępie, rodzaj Cuscuta powoduje znaczne szkody w uprawach na całym świecie. W Polsce, co prawda, Cuscuta lupuliformis jest rośliną 
Tabela 1. Wykaz gatunków żywicielskich Cuscuta lupuliformis na badanych stanowiskach w Sandomierzu

Table 1. List of Cuscuta lupuliformis hosts at the studied localities in Sandomierz

\begin{tabular}{|c|c|c|c|c|c|c|c|c|c|c|c|c|}
\hline $\begin{array}{l}\text { Nr stanowiska } \\
\text { (Locality number) }\end{array}$ & & 1 & 2 & 3 & 4 & 5 & 6 & 7 & 8 & 9 & 10 & \multirow{3}{*}{$\begin{array}{l}\text { Zagęszczenie } \\
\text { pędów pasożyta } \\
\text { na roślinach } \\
\text { żywicielskich } \\
\text { (Shoot density of } \\
\text { the parasite on host } \\
\text { plants) }\end{array}$} \\
\hline $\begin{array}{l}\text { Powierzchnia } \\
\text { (Area) [ha] }\end{array}$ & & 2,2 & 0,1 & 0,5 & 0,3 & 0,8 & 0,6 & 0,2 & 0,2 & 1,1 & 0,2 & \\
\hline $\begin{array}{l}\text { Lokalizacja wg ATPOL } \\
\text { (ATPOL square) } \\
(1 \times 1 \mathrm{~km})\end{array}$ & $\begin{array}{l}\text { Rodzina } \\
\text { (Family) }\end{array}$ & 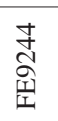 & $\begin{array}{l}\text { ñ } \\
\text { ஸ్ț }\end{array}$ & 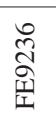 & 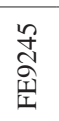 & 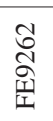 & 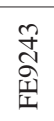 & 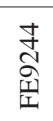 & 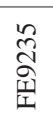 & $\begin{array}{l}\text { กิ } \\
\text { న̂ } \\
\text { III }\end{array}$ & 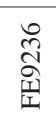 & \\
\hline Acer negundo & Aceraceae & . & . & . & . & . & . & + & . & . & . & $\mathrm{L}$ \\
\hline Acer platanoides & Aceraceae & . & . & . & . & . & . & + & . & . & . & $\mathrm{Z}$ \\
\hline Artemisia vulgaris & Asteraceae & . & . & . & . & . & . & + & + & . & . & $\mathrm{Z}$ \\
\hline Chaerophyllum bulbosum & Apiaceae & . & . & + & . & + & + & + & . & . & . & $\mathrm{L}$ \\
\hline Cirsium arvense & Asteraceae & . & . & . & . & + & . & . & . & . & . & $\mathrm{L}$ \\
\hline Elymus repens & Poaceae & . & . & . & . & . & . & . & . & . & + & $\mathrm{L}$ \\
\hline Erigeron anпииs & Asteraceae & . & . & . & . & . & . & + & . & . & . & $\mathrm{L}$ \\
\hline Fraxinus excelsior & Oleaceae & . & . & . & . & . & . & + & . & . & . & $\mathrm{Z}$ \\
\hline Humulus lupulus & Cannabaceae & . & . & . & . & + & . & + & . & . & . & $\mathrm{L}$ \\
\hline Hypericum perforatum & Hypericaceae & . & . & . & . & + & . & . & . & . & . & $\mathrm{L}$ \\
\hline Lactuca serriola & Asteraceae & . & . & . & . & . & . & + & . & . & . & $\mathrm{L}$ \\
\hline Lonicera tatarica & Caprifoliaceae & . & . & . & . & . & . & + & . & . & . & $\mathrm{Z}$ \\
\hline Malus domestica & Rosaceae & . & . & . & . & . & . & + & . & . & + & $\mathrm{L}$ \\
\hline Phalaris arundinacea & Poaceae & . & . & . & + & . & . & . & + & . & . & $\mathrm{L}$ \\
\hline Populus alba & Salicaceae & . & . & . & . & . & . & + & . & . & . & $\mathrm{L}$ \\
\hline Populus nigra var. italica & Salicaceae & . & . & . & . & . & . & + & . & . & . & $\mathrm{L}$ \\
\hline Prunus cerasifera & Rosaceae & . & . & . & . & . & . & + & . & . & . & $\mathrm{L}$ \\
\hline Prunus spinosa & Rosaceae & . & . & . & . & . & . & + & . & . & . & $\mathrm{L}$ \\
\hline Robinia pseudoacacia & Fabaceae & . & . & . & . & . & . & . & + & . & . & $\mathrm{L}$ \\
\hline Rosa canina & Rosaceae & . & . & . & . & . & . & + & . & . & + & $\mathrm{Z}$ \\
\hline Rubus caesius & Rosaceae & + & + & + & + & + & . & + & . & + & . & $\mathrm{Z}$ \\
\hline Salix alba & Salicaceae & + & . & + & + & + & + & + & + & + & . & $\mathrm{Z}$ \\
\hline Salix fragilis & Salicaceae & . & + & + & + & . & + & + & . & + & . & $\mathrm{Z}$ \\
\hline Salix purpurea & Salicaceae & . & . & . & . & + & + & . & + & + & . & $\mathrm{L}$ \\
\hline Salix viminalis & Salicaceae & + & . & . & . & + & + & . & + & + & . & $\mathrm{Z}$ \\
\hline Sambucus nigra & Caprifoliaceae & . & . & . & . & . & . & + & . & . & . & $\mathrm{Z}$ \\
\hline Solidago canadensis & Asteraceae & . & . & . & + & . & . & + & . & . & + & $\mathrm{L}$ \\
\hline Tanacetum vulgare & Asteraceae & . & . & . & . & . & . & + & . & . & . & $\mathrm{L}$ \\
\hline Ulmus minor & Ulmaceae & . & . & . & . & . & . & + & . & . & . & $\mathrm{L}$ \\
\hline Urtica dioica & Urticaceae & . & . & . & + & + & . & + & . & + & + & $\mathrm{L}$ \\
\hline Valeriana officinalis & Valerianaceae & . & . & . & . & . & . & . & . & . & . & $\mathrm{L}$ \\
\hline
\end{tabular}

Objaśnienia (Abbreviations): L - łodygi luźno oplatające rośliny żywicielskie (stems loosely enveloping host plants), $\mathrm{Z}$ - zwarte płaty (dense lobes).

jednoroczną, której zasięg jest ograniczony do dolin większych rzek, jednak nie jest wykluczone, że w przyszłości gatunek ten może infekować uprawy drzew lub krzewów owocowych zakładanych w tym regionie.

Summary. Host preferences of Cuscuta lupuliformis (Convolvulaceae) in Sandomierz. The paper presents data on the occurrence of host plants of Cuscuta lupuliformis, indicating the preferred species 
and assessing the parasite's development. Field research was conducted in 2017-2018 along the Vistula river valley within the city of Sandomierz (S Poland). Thirty-one host plants belonging to 14 families were identified. Dodder infected mainly Chaerophyllum bulbosum, Salix alba, S. fragilis, S. purpurea, S. viminalis, Rubus caesius and Urtica dioica. The families most attacked were Salicaceae, Asteraceae and Rosaceae (Fig. 1). Dodder intensively attacks species such as Acer platanoides, Artemisia vulgaris, Fraxinus excelsior, Lonicera tatarica, Salix alba, S. fragilis, S. viminalis, Rosa canina, Rubus caesius and Sambucus nigra. The diversity of hosts was highest near the city center. One dodder plant can parasitize several unrelated host species at the same time.

\section{LITERATURA}

BARÁth K. \& CSIKY J. 2012. Host range and host choice of Cuscuta species in Hungary. - Acta Botanica Croatica 71(2): 215-227.

Benvenuti S., Dinelli G., Bonetti A. \& Catizone P. 2005. Germination ecology, emergence and host detection in Cuscuta campestris. - Weed Research 45(4): 270-278.

BoRYSIAK J. 1994. Struktura aluwialnej roślinności lądowej środkowego i dolnego biegu Warty. s. 258. Uniwersytet A. Mickiewicza, Poznań.

Costea M. \& TARDif F. J. 2006. The biology of Canadian weeds. 133. Cuscuta campestris Yuncker, C. gronovii Willd. ex Schult., C. umbrosa Beyr. ex Hook., C. epithymum (L.) L. and C. epilinum Weihe. - Canadian Journal of Plant Science 86(1): 293-316.

Costea M., García M. A. \& Stefanović S. 2015. A phylogenetically based infrageneric classification of the parasitic plant genus Cuscuta (dodders, Convolvulaceae) - Systematic Botany 40(1): 269-285.

Costea M., Stefanović S., García M., Cruz S., Casazza M. \& Green A. 2016. Waterfowl endozoochory: an overlooked long-distance dispersal vector for Cuscuta (dodder). -American Journal of Botany 103(5): 957-962.

Dyderski M. K. \& WroŃSKa-PilareK D. 2015. Szata roślinna nowo powstałych użytków ekologicznych „Dębina I” oraz „Dębina II” w Poznaniu. - Nauka Przyroda Technologie 9(4): 1-21.

GaJewsKi W. 1962. Pasożytnicze rośliny kwiatowe. s. 78. Państwowe Zakłady Wydawnictw Szkolnych, Warszawa.

HeIDE-Jørgensen H. S. 2008. Parasitic flowering plants. s. 438. Brill, Leiden, The Netherlands.

Kaiser B., Vogg G., Fürst U. B. \& Albert M. 2015. Parasitic plants of the genus Cuscuta and their interaction with susceptible and resistant host plants. - Frontiers in Plant Science 6: 1-9.

KĘPCZYŃSKI K. \& RUTKOWSKI L. 1981. Zbiorowiska wodne, szuwarowe i zaroślowe na odcinku Wisły Nebrowo Wlk. - Jarzębina. - Studia Societatis Scientiarum Torunensis, Sectio D, 11(3): 3-35.

Lanini W. T. \& Kogan M. 2005. Biology and management of Cuscuta in crops. - Ciencia e Investigación Agraria 32: 127-141.

Mirek Z., PięKoś-Mirkowa H., ZająC A. \& ZająC M. 2002. Flowering plants and pteridophytes of Poland. A checklist. - W: Z. MireK (red.), Biodiversity of Poland. 1, s. 442. W. Szafer Institute of Botany, Polish Academy of Sciences, Kraków.

Podbielkowski Z. \& Podbielkowska M. 1992. Przystosowania roślin do środowiska. s. 583. Wydawnictwa Szkolne i Pedagogiczne, Warszawa.

Sharma Y. P. \& KAPOOR V. 2014. Parasitic angiosperms and biology of Cuscuta species - an overview. - Annual Review of Plant Pathology 6: 577-608.

Schmitz U. \& Lösch R. 1995. Vorkommen und Soziologie der Cuscuta-Arten in der Ufervegetation des Niederrheins. - Tuexenia 15: 373-385.

The Plant List. 2013. Version 1.1. http://www.theplantlist.org/ (dostęp: 14.05.2019). 
WaYda M. 1999. Rozmieszczenie Cuscuta lupuliformis (Cuscutaceae) w Polsce. - Fragmenta Floristica et Geobotanica Series Polonica 6: 75-81.

ZAJĄC A. 1978. Założenia metodyczne „Atlasu rozmieszczenia roślin naczyniowych w Polsce”. - Wiadomości Botaniczne 22(3): 145-155.

Michalina PaneK-WóJcicka (autor korespondencyjny), Renata Piwowarczyk, Centrum Badań i Ochrony Różnorodności Biologicznej, Instytut Biologii, Uniwersytet Jana Kochanowskiego, ul.Uniwersytecka 7, 25-406 Kielce, Polska; e-mail: michalinapanek@wp.pl, renata.piwowarczyk@ ujk.edu.pl

Wptynęto: 12.01.2020 r.; przyjęto do druku: 24.11.2020 r.

DOI: https://doi.org/10.35535/ffgp-2020-0050

\section{Nowe stanowisko Asperugo procumbens (Boraginaceae) w Niecce Nidziańskiej}

Asperugo porcumbens L. (lepczyca rozesłana), to jednoroczna roślina zielna należąca do monotypowego rodzaju Asperugo L. Jest przedstawicielem rodziny ogórecznikowatych Boraginaceae. Płożąca się lub rzadziej wznosząca gałęzista łodyga, pokryta jest drobnymi haczykowatymi kolcami. Dorasta do 60 cm długości (RUTKOwski 2004). Podługowato eliptyczne liście wyrastają po trzy z okółka. Drobne kwiaty pojawiają się na przełomie maja i czerwca po kilka w kątach liści. Zrosłopłatkowa korona początkowo purpurowofioletowa w trakcie rozwoju zmienia kolor na niebieski. Jedynie rurka i osklepki pozostają białe. Kielich o pięciu lancetowato wydłużonych, kolczasto owłosionych działkach, po przekwitnięciu powiększa się i spłaszcza grzbietobrzusznie (Ryc. 1). Pomiędzy siatkowato unerwionymi dwoma klapami znajduje się owoc - rozłupnia, zbudowana z czterech pokrytych brodawkami rozłupek (Ryc. 1; SUDNIK-WóJCIKOWSKA 2011).

Asperugo procumbens jest gatunkiem ruderalnym. W Polsce występuje niezbyt często, głównie na niżu (Ryc. 2; ZAJĄC \& ZAJĄC 2001).

Podobnie jak w przypadku innych archeofitów, w ostatnich dziesięcioleciach obserwowany był duży spadek liczby stanowisk Asperugo procumbens w Polsce (ZARZYCKI i in. 2002). W 2006 r. gatunek został uznany za wymierający w Polsce (kategoria E; ZARZYCKI \& SzELĄG 2006), a dziesięć lat później zmieniono jego kategorię na NT - bliski zagrożenia (KAŹMIERCZAKOWA i in. 2016). Lepczyca rozesłana została także umieszczona na liście zagrożonych archeofitów jako gatunek narażony na wyginięcie (kategoria VU; ZAJĄC \& ZAJĄC 2014). Na regionalnej liście gatunków zagrożonych Wyżyny Małopolskiej również uzyskała kategorię VU (BRóż \& PRZEMYSKi 2009).

Z terenu Niecki Nidziańskiej Asperugo procumbens znana była jedynie z czterech stanowisk, tj. ze Skorocic w Niecce Soleckiej (MEDwECKA-KorNAś 1959; SzwagrZyK 1987) oraz Topoli, Kowali i Witowa na Płaskowyżu Proszowickim (TowPAsz i in. 2002; TowPAsz 2006). 